\title{
Matemática e Surrealismo
}

\section{Mathematics and Surrealism}

\author{
Djeison Benetti* \\ ORCID iD 0000-0002-9306-8797 \\ Vinicius Machado Pereira dos Santos ${ }^{* *}$ \\ ORCID iD 0000-0001-8005-9229 \\ Aldi Nestor de Souza ${ }^{* * *}$ \\ ORCID iD 0000-0001-6858-4821
}

\begin{abstract}
Resumo
Neste trabalho fazemos uma análise da Matemática a partir da teoria crítica da sociedade da Escola de Frankfurt, tendo o Surrealismo como referência. Lembramos que entrelaçamentos entre Educação e Teoria Crítica já foram feitos em muitos trabalhos, inclusive em Educação Matemática: por exemplo, Adorno (2012), Pucci, Zuin e Ramos-de-Oliveira (2004) e Skovsmose (2015). O Surrealismo, por sua vez, surge como um movimento de vanguarda construído em torno de questionamentos artísticos, intelectuais e políticos, cujas ideias revolucionárias são contra qualquer imposição totalizante que implique em uma formatação do pensamento. Nossa abordagem, portanto, faz uma tentativa de abertura das possibilidades de pensamento em Matemática, estando na direção dos pontos elencados por Miguel (2016) para uma agenda contemporânea da Educação Matemática brasileira. Além disso, repensar o papel político da Matemática e, por consequência, da Educação Matemática é urgente e nada mais significativo do que recorrer à Escola de Frankfurt e ao Surrealismo, isto é, aqueles que viveram e escreveram a partir de experiências totalitárias.
\end{abstract}

Palavras-chave: Matemática. Educação. Teoria Crítica. Psicanálise. Surrealismo.

\begin{abstract}
In this work, we analyzed Mathematics from the Frankfurt School critical society theory having surrealism as reference. We emphasize that education and critical theory have already been studied in many works, including in mathematics education: for example, Adorno (2012), Pucci, Zuin and Ramos-de-Oliveira (2004) and Skovsmose (2015). Surrealism emerges as a vanguard movement built on artistic, intellectual, and political issues, which revolutionary ideas are against any totalizing imposition that implies thought formatting. Our approach, therefore, is an attempt to open the thought possibilities in mathematics, in the direction of the points

\footnotetext{
* Doutor em Matemática pela Universidade Estadual de Maringá (UEM). Professor da Universidade Federal de Mato Grosso (UFMT), Cuiabá, Mato Grosso, Brasil. Endereço para correspondência: departamento de Matemática/ICET/UFMT, Avenida Fernando Correa da Costa, 2367, Boa Esperança, Cuiabá, Mato Grosso, Brasil, CEP: 78060-900. E-mail: djeisonbenetti@gmail.com.

** Doutor em Educação em Ciências e Matemática pela Universidade Federal de Mato Grosso (UFMT). Professor da Universidade Federal de Mato Grosso (UFMT), Cuiabá, Mato Grosso, Brasil. Endereço para correspondência: departamento de Matemática/ICET/UFMT, Avenida Fernando Correa da Costa, 2367, Boa Esperança, Cuiabá, Mato Grosso, Brasil, CEP: 78060-900. E-mail: viniciusmps@ gmail.com.

**** Doutor em Matemática pela Universidade Federal Fluminense (UFF). Professor da Universidade Federal de Mato Grosso (UFMT), Cuiabá, Mato Grosso, Brasil. Endereço para correspondência: departamento de Matemática/ICET/UFMT, Avenida Fernando Correa da Costa, 2367, Boa Esperança, Cuiabá, Mato Grosso, Brasil, CEP: 78060-900. E-mail: aldinestor@ufmt.br.
} 
listed by Miguel (2016) for a contemporary agenda of the Brazilian mathematical education. Rethinking the political role of mathematics and, consequently, mathematical education is urgent and there is nothing more significant than resorting to the Frankfurt School and surrealism, that is, to those who lived and wrote from totalitarian experiences.

Keywords: Mathematics. Education. Critical theory. Psychoanalysis. Surrealism.

\section{Introdução}

Neste trabalho fazemos uma análise da Matemática a partir da teoria crítica da sociedade da Escola de Frankfurt, tendo o Surrealismo como referência. Primeiro, destacamos que o Surrealismo, enquanto movimento organizado, surgiu entre as duas grandes guerras e suas principais ideias são encontradas em dois manifestos escritos por André Breton, o primeiro em 1924 e o segundo em 1929. No impulso criativo original surrealista, evidencia-se a influência da psicanálise freudiana na constituição dos seus métodos, bem como a associação deles a uma crítica social radical, apoiada nas ideias marxistas e reconhecida pelo próprio Walter Benjamin: "No momento, os surrealistas são os únicos que conseguiram compreender as palavras de ordem que o Manifesto [Comunista] nos transmite hoje" (1929/2012, p. 36). Segundo, não propomos estudar aqui a apropriação da Matemática feita pelo Surrealismo na composição de suas obras ou ideias ${ }^{1}$. A rigor, entendemos o surrealismo em seu sentido amplo, isto é, enquanto movimento de vanguarda, construído em torno de questionamentos artísticos, intelectuais e políticos, cujas ideias revolucionárias são contra qualquer imposição totalizante que implique em uma formatação do pensamento. A partir disso, fazemos uma condenação ao autoritarismo e à superficialidade, próprios daquele tipo de pensamento que tem na quantificação da realidade o único critério de validação científica, sendo uma característica do que Herbert Marcuse chamou de pensamento unidimensional. De fato, ao optarmos por tal exclusivismo também optamos pela falta de entendimento da própria Matemática, - com consequências profundas nas concepções de Educação Matemática -, culminando hoje no que poderíamos chamar, inspirados por Theodor W. Adorno ${ }^{2}$, de um prevalecimento de uma Matemática ligeira em detrimento de uma Matemática séria.

Ainda não estamos aptos a fazer uma distinção formal entre uma Matemática que julgamos séria e outra, inferior, que julgamos ligeira. Mas, no que segue, insistimos na

\footnotetext{
${ }^{1}$ Mesmo assim não podemos deixar de mencionar o exemplo de Marcel Duchamp que intentou usar conceitos de geometria não-euclidiana em alguns de seus trabalhos.

${ }^{2}$ Inspiração que vem do livro de Adorno, Introdução à Sociologia da Música, mais precisamente o capítulo Música ligeira.
} 
concepção de que as instituições de Educação no capitalismo avançado propagam os fundamentos de uma Matemática que curiosamente parecem não ter relação - ou, ao menos, não ter mais relação direta - com a moderna produção de mercadorias. Não podemos negar que a Matemática de ponta, bem como qualquer matemática utilizada na produção de ponta, é feita e executada por grupos seletos em centros especializados. Mesmo aquelas áreas que utilizam tradicionalmente a Matemática, como a Engenharia, a Administração ou a Física, já a fazem a partir de modelos pré-fabricados ou com ínfimas adequações de um mesmo método. É justamente porque se exige constantemente o resultado (esperado!) que mantém-se o já consagrado.

Contudo, mesmo a inovação técnica dificilmente se faz mediante só a técnica. Acreditamos que espaço e tempo, ao invés de sacrificados na repetição, precisam adquirir uma dimensão subversiva. Assim sendo, não estamos interessados em encontrar meios que diminuam o afastamento entre prática e teoria numa busca pelo entendimento da participação da Matemática na reprodução material da vida - pelo menos não da maneira como tradicionalmente esse tema é abordado em Educação Matemática. Nossa aproximação entre Matemática e realidade se dá na exigência por um novo afastamento, qualitativamente diferente.

Pretendemos explorar tal possibilidade para a Matemática a partir da perspectiva surrealista e da teoria crítica da sociedade da Escola de Frankfurt. Para tanto, lembramos, por um lado, que entrelaçamentos entre Educação e Teoria Crítica já foram feitos em muitos trabalhos, inclusive em Educação Matemática: por exemplo, Adorno (2012), Pucci, Zuin e Ramos-de-Oliveira (2004) e Skovsmose (2015). Por outro lado, nossa abordagem faz uma tentativa de abertura das possibilidades de pensamento em Matemática, estando, portanto, na direção dos pontos elencados por Miguel (2016) para uma agenda contemporânea da Educação Matemática brasileira. Repensar o papel político da Matemática e, por consequência, da Educação Matemática é sempre importante. Diante da ameaça de retrocessos políticos ou mesmo de estados de exceção, tal tarefa torna-se urgente e nada mais significativo do que recorrer à Escola de Frankfurt e ao Surrealismo, isto é, aqueles que viveram e escreveram a partir de experiências totalitárias.

\section{Em busca de uma subversão da realidade}

Entre as ciências, a Matemática parece adquirir uma posição singular precisamente porque, a partir da modelagem da experiência, pode voltar-se para o desenvolvimento de seus 
próprios conteúdos abstratos (Matemática pura). Quanto à Educação, portanto, percebemos que há um descompasso entre os desenvolvimentos da Matemática e o que se ensina em sala de aula, pois hoje dificilmente estabelecemos uma relação fecunda entre a abstração matemática e seus diferentes usos na reprodução material da vida. Sendo a Matemática motivação para muitas pessoas que estudam, trabalham e promovem discussões, o que nos interessa aqui não é uma condenação da Matemática e de sua abstração, mas a constatação que - socialmente - há a promoção de um tipo de Matemática cuja função é justamente aquilo que os educadores apontam como insucesso: a repressão de muitos com consequente promoção de eleitos. Para tanto, o que permanece para todos é a imposição de uma Matemática rasa, ligeira, que não contribui para o aprimoramento do ser humano, antes está a serviço da seleção e da difusão de padrões de comportamento e pensamento que conduzem à perpetuação das divisões de classe e à aceitação do universo de coisas estabelecido.

Com efeito, como veremos, há um movimento coordenado de desvalorização ou eliminação de tudo o que é considerado supérfluo, excedente. Significativa, por exemplo, foi a situação vivenciada ao se ministrar a disciplina de Cálculo Diferencial e Integral em um curso de Química. Havia um desinteresse da maioria dos alunos e o cálculo era taxado como desnecessário, um empecilho à formação. Em certa aula, numa tentativa de aproximação pelo diálogo, os alunos foram questionados se sabiam algo sobre o noticiado à época: a compra da Monsanto pela Bayer. Ninguém sabia o que se passava entre duas potências da indústria química moderna, tampouco sabiam da seguinte história: a IG Farben foi uma companhia formada pela junção das maiores indústrias químicas da Alemanha e, durante a Segunda Guerra Mundial, a serviço do nazismo, utilizava trabalho escravo em suas fábricas e produzia o pesticida para as câmaras de gás. Com o fím da guerra, a empresa foi novamente desmembrada em suas subsidiárias, dentre elas a Bayer. Aqui, para os futuros químicos e professores de Química, tanto a história como a Matemática parecem ocupar lugar dentre os saberes indesejados. De fato, muitas vezes desconexa de um sentido imediatamente visível para aqueles que a estudam, a Matemática causa descontentamento e já não raro é colocada como algo supérfluo, um excedente desnecessário que, pelas dificuldades inerentes a seu estudo, é mais um entrave para a formação do que um saber com algum valor próprio. Tal situação, antes de ser um sintoma isolado, possui seus reflexos até entre aqueles que estudam Engenharia, uma vez que softwares especializados são capazes de apresentar os resultados desejados automaticamente. Apesar disso, insistimos num ponto: mesmo sob protestos, a Matemática sobrevive enquanto Matemática ligeira, isto é, enquanto for eficiente em seu papel de seleção e enquadramento do pensamento. 
No ensino da Matemática e na organização dos cursos de licenciatura em Matemática a eliminação do excedente vem sendo particularmente notável. Primeiro, negligencia-se toda a Matemática considerada "pesada demais" com a rasa argumentação de que um professor de Matemática do Ensino Básico não a utiliza na execução de suas aulas. Cabe ressaltar que esta negligência se dá em duas frentes: na exclusão e na falsificação dos conteúdos. Por falsificação entendemos, por exemplo, a simplificação demasiada, característica de cursos preparatórios para exames de acesso, e a ênfase excessiva nos elementos lógicos e algébricos em detrimento da própria constituição histórica do conhecimento. É ilustrativo a negligência com relação ao estudo da geometria elementar, das geometrias não-euclidianas e da topologia. Segundo, há uma minimização do debate educacional: ao invés de se discutir educação e suas implicações gerais, discute-se a educação restrita ao ensino e aprendizagem da Matemática que, no predomínio de uma intencionalidade prática, acaba por esvaziar-se ainda mais na elaboração de métodos ou de "oficinas mais adequadas" para se ensinar tal ou qual conteúdo. E a "execução" prossegue: da história para a história da Matemática, da sociologia geral para a sociologia das ciências, da psicologia/psicanálise para a psicologia escolar behaviorista, da filosofia para a lógica e assim por diante.

Entretanto, não se trata apenas de uma questão de currículo, pois da escola à universidade há um esforço constante contra o desenvolvimento da espontaneidade na opção por um imediatismo lógico-prático, uma "oficinalização", cujo material para o pensamento é sistematicamente eliminado, levando, por fim, à exclusão do próprio pensamento: a Educação repete o exigido pela divisão social do trabalho. Em particular, a imposição de uma matemática ligeira se dá no estabelecimento de uma forma e conteúdo unidimensionais a serviço do estrangulamento do pensamento autônomo, da subjetividade mesma. A existência do hábil matemático, independentemente do "grau" de sua autonomia, antes atesta a eficácia desses mecanismos.

No atual e crescente quadro de insensibilidade, nos perguntamos: será que a opção por uma realidade descomprometida em fornecer material para o pensamento não é expressão, ao mesmo tempo, de um descaso com o próprio fundamento da razão que legitima a ciência burguesa enquanto suposta busca pela verdade? Ou ainda: será que a opção por um esvaziamento do pensamento não fomenta uma alienação extremada que conduz ao predomínio de fantasias - potencialmente fascistas - sobre a realidade?

Diante de tais especulações, buscamos refúgio na arte, pois a função da obra de arte autêntica também é criar uma outra realidade só que, pelo próprio movimento de afastamento que ela deve provocar, sobrepõe o imediatamente dado da existência sem perder o nexo com a 
realidade na sua acusação. De fato:

\begin{abstract}
A separação da arte do processo de produção material deu-lhe a possibilidade de desmistificar a realidade reproduzida neste processo. A arte desafia o monopólio da realidade que o existente possui e fá-lo criando um mundo fictício que, no entanto, é mais real do que a própria realidade. Atribuir as qualidades críticas, autônomas da arte à forma estética é colocá-las fora da literatura de tendência, fora do domínio da práxis e da produção. A arte tem sua própria linguagem e ilumina a realidade através desta outra linguagem. Além disso, a arte tem sua própria dimensão de afirmação e negação, uma dimensão que não se pode ordenar relativamente ao processo social de produção (MARCUSE, 2007, p. 29).
\end{abstract}

Conforme Marcuse (2007), a mudança qualitativa da realidade pressupõe mais do que consciência política e a importância da arte surge da possibilidade de elaboração de uma sensibilidade, imaginação e razão emancipadas do domínio da exploração, pois:

A arte é uma força qualitativamente diferente do trabalho; as suas qualidades essencialmente subjetivas afirmam-se contra a dura objetividade da luta de classes. $\mathrm{O}$ escritor, que, na sua obra, se identifica com o proletariado, continua a ser marginal - por muito que renuncie a forma estética a favor da expressão e da comunicação direta. Continua a ser marginal não por causa da sua origem e educação nãoproletária, do seu afastamento do processo de produção material, de seu "elitismo", mas devido à transcendência essencial da arte que torna o conflito entre a arte e a práxis política inevitável. O surrealismo, no seu período revolucionário, atestou esse conflito inerente entre a arte e o realismo político. A possibilidade de uma aliança entre "o povo" e a arte pressupõe que os homens e as mulheres administrados pelo capitalismo cosmopolita desaprendam a linguagem, os conceitos e as imagens desta administração, que experimentem a dimensão da mudança qualitativa, que reivindiquem a sua subjetividade, a sua interioridade (MARCUSE, 2007, p. 39-40).

É nesta desaprendizagem da linguagem, dos conceitos e das imagens da administração estabelecida que o Surrealismo passa a ser interessante para nós. De fato, o método surrealista se baseia em uma transfiguração da percepção feita pela via da escrita automática, da anotação dos sonhos, da vizinhança com a loucura, a alucinação e o delírio, cujo propósito vai além do caráter estético e das delimitações artísticas (WILLER, 1985, p. 17). Em resumo, o Surrealismo busca subverter a realidade tal como expresso em sua própria definição:

SURREALISMO, s. m. Automatismo psíquico puro pelo qual se propõe exprimir, seja verbalmente, seja por escrito, seja de qualquer outra maneira, o funcionamento real do pensamento. Ditado do pensamento, na ausência de todo controle exercido pela razão, fora de toda preocupação estética ou moral.

ENCICL. Filos. O surrealismo repousa sobre a crença na realidade superior de certas formas de associações desprezadas antes dele, na onipotência do sonho, no desempenho desinteressado do pensamento. Tende a demolir definitivamente todos os outros mecanismos psíquicos, e a se substituir a eles na resolução dos principais problemas da vida (BRETON, 1985, p. 58).

As possibilidades de sensibilidade, imaginação e razão inteiramente novas, defendidas por Marcuse (2007) como critérios essenciais para a transformação qualitativa da realidade, estão também evidentemente presentes na descrição do Surrealismo feita por Octávio Paz:

O surrealismo recusa-se a ver o mundo como um conjunto de coisas boas e más, umas preenchidas pelo ser divino e outras roídas pelo nada; daí seu anticristianismo. 
Da mesma forma, nega-se a ver a realidade como um conglomerado de coisas úteis ou nocivas; daí seu anticapitalismo. As ideias de moral e de utilidade lhe são estranhas. Finalmente, tampouco considera o mundo à maneira do homem de ciência puro, ou seja, como objeto ou grupo de objetos desnudados de todo valor, desprendidos do espectador. Nunca é possível ver o objeto em si: sempre está iluminado pelo olho que mira, sempre está moldado pela mão que acaricia, o oprime ou o empunha. $\mathrm{O}$ objeto, instalado em sua realidade irrisória como um rei em um vulcão, imediatamente muda de forma e se transforma em outra coisa. $\mathrm{O}$ olho que o mira o amolece como cera; a mão que o toca o modela como argila. $\mathrm{O}$ objeto se subjetiviza. (...) Evidentemente, trata-se do mesmo objeto, apenas servindo a poderes distintos. E assim inicia-se uma vasta transformação da realidade. Filho do desejo, nasce o objeto surrealista: o conjunto de montanhas é outra vez um cenário de gigantes, as manchas da parede recobram vida, põem-se a voar e são um exército de aves que com seus bicos terríveis dilaceram o ventre da bela acorrentada (PAZ apud WILLER, 1985, p. 16).

Importante para Marcuse (2007) é o afastamento que a arte pode e deve assumir com relação "ao povo" quando este não representa mais aquilo que era o proletariado para Marx, isto é, os agentes de uma transformação qualitativa da realidade na constituição de uma sociedade sem classes. A arte autêntica se afasta da identificação imediata com o universo de coisas estabelecido e fornece novas possibilidades que não aquelas restritas à lógica e ao modo de produção capitalista. Subversão que surge da arte como acusação e promessa: acusação da realidade repressiva e promessa de felicidade por se realizar. Subversão, portanto, que surge no inusitado encontro de uma criança com um objeto qualquer que transforma em brinquedo, como nos afirma o próprio fundador da psicanálise:

Não deveríamos buscar já na infância os primeiros traços de atividade criativa? A
ocupação mais querida e mais intensa da criança é a brincadeira. Talvez possamos
dizer que toda criança, ao brincar, se comporta como um criador literário, pois
constrói para si um mundo próprio, ou, mais exatamente, arranja as coisas de seu
mundo numa ordem nova, do seu agrado. Seria errado, portanto, pensar que ela não
toma a sério esse mundo; pelo contrário, ela toma sua brincadeira muito a sério, nela
gasta grande montantes de afeto. O oposto da brincadeira não é a seriedade, mas sim
- a realidade. Não obstante todo o investimento de afeto, a criança distingue muito
bem da realidade o seu mundo de brincadeira, e gosta de basear nas coisas palpáveis
e visíveis do mundo real os objetos e situações que imagina. É esse apoio na
realidade que distingue o seu "brincar" do "fantasiar". O escritor faz o mesmo que a
criança ao brincar; constrói um mundo de fantasia que leva bastante a sério, ou seja,
dota de grande montantes de afeto, ao mesmo tempo que os separa claramente da
realidade (FREUD, 1908/2016, p. 326-327).

Aqui temos, com efeito, uma pequena revolução: o brincar infantil subverte o imediatamente dado da coisa ao transformá-la pelo viés da imaginação. Enquanto a coisa em si está condenada a uma existência e execução únicas no tempo, a brincadeira, em sua insistente capacidade deformativa, suspende a sua condenação espacial e temporal. O livre brincar infantil antes mesmo de obedecer regras, busca controlá-las ou aniquilá-las. Mesmo que o resultado seja o apaziguamento das tensões, isto não ocorre sem antes negar e conduzir 
a realidade para um domínio próprio de aceitação ${ }^{3}$. Passa-se assim, tanto pela arte autêntica como pela brincadeira, do imediatismo executório para uma relação mediada com a realidade, isto é, sublimada. O Surrealismo em suas ideias e métodos corresponde exatamente a tal perspectiva, restando a nós, portanto, analisarmos em que circunstâncias uma Matemática verdadeiramente comprometida com o pensamento pode se valer disso.

\section{Sobre deformações e colagens}

Em Matemática, as palavras deformação e colagem nos conduzem à área da geometria conhecida como topologia. Inicialmente sem uma caracterização específica, isto é, enquanto ramo da Matemática propriamente dito, as primeiras realizações da topologia incluem descobertas isoladas ainda nos séculos XVII e XVIII, como a fórmula de Euler V-A+F=2. Mas é somente nos séculos XIX e XX que a topologia adquiriu fundamentação e se tornou uma área de pesquisa proeminente. A partir do desenvolvimento da teoria dos conjuntos e da álgebra moderna, legítimas no aprimoramento da linguagem matemática e necessárias para a generalização de resultados, a topologia evoluiu ao mesmo tempo em que se afastou das inspirações e motivações iniciais ${ }^{4}$. Assim sendo, não podemos ficar alheios aos possíveis reflexos de um conhecimento que se afasta da perspectiva original de sua concepção e passa a uma abstração intensificada. Atentamos, portanto, para um sintoma que parece ser a expressão comum da Educação moderna: a perda dos estímulos à capacidade criativa.

Lembramos que, enquanto a geometria elementar trabalha com grandezas

\footnotetext{
${ }^{3}$ Significativo é o exemplo dado por Freud ao descrever e interpretar a brincadeira de uma criança em Além do princípio do prazer (1920/2010, p. 170-175).

${ }^{4}$ Para que o leitor veja por si mesmo sugerimos os seguintes textos: Topology de Aleksandrov (1999), Initiation to Combinatorial Topology de Fréchet e Fan (1969) e aquele que parece ser o mais conhecido atualmente entre os matemáticos, Topology de Munkres (2000). Não queremos dizer com isso que vinculamos a existência da topologia ao problema das pontes de Königsberg - ou, por exemplo, o que seria equivalente, a existência do cálculo avançado aos métodos de Arquimedes -, mas apontamos para algo presente nas motivações iniciais da topologia que se perde ao se estabelecerem as formalizações da matemática moderna em termos da álgebra e da teoria dos conjuntos. Nesse sentido, Marcuse (2015) alerta: “(...) o mundo objetivo, equipado apenas com qualidades quantificáveis, vem a ser mais e mais dependente do sujeito para sua objetividade. Esse longo processo começa com a algebrização da geometria, que substitui figuras geométricas 'visíveis' por operações puramente mentais. Ele encontra sua forma extrema em algumas concepções da filosofia científica contemporânea, de acordo com a qual toda questão relativa à ciência física tende a desaparecer em relações matemáticas ou lógicas. A própria noção de uma substância objetiva oposta ao sujeito, parece desintegrar. A partir de condições muito diferentes, cientistas e filósofos da ciência chegam a hipóteses similares sobre a exclusão de tipo particulares de entidades. Por exemplo, a física 'não mede as qualidades objetivas do mundo externo e material - estas são apenas os resultados obtidos pela realização de tais operações'. Os objetos continuam a persistir apenas como 'intemediários convenientes', como 'postulados culturais obsoletos'. A densidade e a opacidade das coisas evaporam: o mundo objetivo perde seu 'caráter objetificável', sua oposição ao sujeito. Aquém de sua interpretação em termos da metafísica pitagórico-platônica, a Natureza matematizada, a realidade científica parece ser uma realidade ideacional” (p. 156-157).
} 
(comprimento, ângulo e área) que não são alteradas por movimentos rígidos, a topologia é o ramo da geometria que trabalha com as propriedades topológicas das figuras, dentre elas a dimensionalidade, a conexidade, a compacidade e a orientabilidade. Uma transformação topológica é aquela que preserva as propriedades topológicas e um dos exemplos mais intuitivos desse tipo de transformação são as deformações. Grosso modo, podemos entender uma deformação como uma transformação que entorta ou estica uma figura, sem que haja rompimentos, cortes ou furos adicionais. Por exemplo, um triângulo pode ser deformado em qualquer outro triângulo, um círculo pode ser deformado em uma elipse e um toro (rosquinha com um furo no meio) pode ser deformado em uma xícara (onde o furo passa a compor a alça da xícara), mas não se pode deformar um círculo em um segmento de reta. Em resumo, podemos dizer que a topologia admite movimentos menos rígidos, pois ao entortar ou esticar uma figura alteramos ângulos, distâncias e áreas, ou seja, as propriedades métricas da Geometria elementar não são mantidas enquanto as propriedades topológicas permanecem as mesmas. De modo geral, as concepções iniciais da topologia e de suas propriedades destacamse pelas exigências visuais a partir da manipulação de figuras, sendo importantes em muitas investigações, como o teorema da curva de Jordan, o teorema das quatro cores, o teorema do ponto fixo e o estudo envolvendo nós e tranças ${ }^{5}$.

Não é comum a topologia fazer parte dos currículos dos cursos de licenciatura em Matemática, cabendo aqui uma observação geral: frequentemente coloca-se como importante para a aprendizagem da Matemática um ensinar menos rígido e maçante e, ao mesmo tempo, pouco se evolui no sentido de uma reestruturação da apresentação dos conteúdos matemáticos no que compete ao fim de suas divisões internas e a ampliação de suas possibilidades. Nessa direção, Pavanello (1989) nos aponta que as decisões relativas à Educação não podem ser vistas fora do contexto histórico, político e social, pois há um motivo ideológico para que o ensino de certos conteúdos em Matemática, principalmente aqueles referentes à Geometria, sejam negligenciados. O estudo de Pavanello refere-se ao Ensino Básico, mas essa é uma tendência que se repete, como já mencionamos, na formação dos professores de Matemática.

$\mathrm{Na}$ verdade, a eliminação do excedente, do pensamento autônomo e da capacidade criativa estão atrelados à ciência burguesa ao impor uma concepção de conhecimento que nos faz acreditar, como dizem Adorno e Horkheimer (2006, p. 23), que todas as grandes descobertas já são projetadas de antemão e todos os grandes pensamentos já foram pensados. Paradoxalmente, a psicanálise surge como uma das últimas grandes realizações da ciência

\footnotetext{
${ }^{5}$ Veja, por exemplo, Courant e Robbins (2000).
} 
burguesa ao mesmo tempo que - do Penso logo sou, cartesiano, para o Sou onde não penso desbanca o indivíduo racional, plenamente consciente e senhor de si do Iluminismo, ao apresentar o sujeito do inconsciente. Em particular, não é à toa que o surrealismo tem nas descobertas de Freud sua maior inspiração e até mesmo a crítica que Jacques Lacan faz da psicanálise pós-freudiana ${ }^{6}$ pode ser estendida a uma crítica à própria Ciência Moderna. Entrelaçamos, portanto, Matemática e Surrealismo no encontro com dois conceitos fundamentais da psicanálise: o inconsciente e a pulsão ${ }^{7}$. Enquanto o Surrealismo em seus próprios fundamentos busca libertar o inconsciente de toda repressão, as atividades intelectuais e artísticas sempre foram valorizadas por Freud pelo desvio da pulsão em formas outras que não a estritamente sexual, isto é, pela sublimação. Passamos então a questionar as possibilidades sublimativas proporcionadas pelo estudo da Matemática.

Em primeiro lugar, recordamos que a inserção da psicanálise na análise das situações de ensino-aprendizagem em Educação Matemática já foram defendidas por Baldino e Cabral (1995, 2010). Em segundo lugar, a complexidade que tal inserção envolve pode ser encontrada ainda em Freud quando nos mostra "como a psique humana se torna, no estado da repressão, sensível à aproximação do que foi reprimido, e como bastam semelhanças mínimas para que este obtenha efeito por trás e através do elemento repressor" (1907/2016, p. 51). Para tanto, se utiliza de um exemplo:

Tive oportunidade, certa vez, de tratar um jovem, quase ainda garoto, que, após a
primeira informação (indesejada) que lhe chegou dos processos sexuais, fugiu de
todos os desejos que nele afloravam, recorrendo a diversos meios de repressão para
isso: intensificou a diligência nos estudos, exacerbou apego infantil na mãe e adotou,
de um modo geral, um comportamento infantil. (...) nosso fugitivo se ocupou, com
zelo especial, da matemática e da geometria ensinadas na escola, até que um dia sua
compreensão falhou repentinamente ante alguns exercícios inocentes. Foi possível
relembrar o teor de dois desses exercícios. Um deles dizia: "Dois corpos se chocam,
um com a velocidade etc.". E o outro: "Num cilindro de diâmetro $m$, inscrever um
cone etc.". Por causa dessas alusões à atividade sexual, que para outros estariam
longe de ser evidentes, ele se sentiu traído pela matemática e fugiu dela também
(FREUD, 1907/2016, p. $51-52$ ).

Agora, enunciamos a proposição: na Matemática Moderna há uma limitação do escopo da sublimação, de modo que o "horror à matemática" - enquanto expressão do fracasso escolar - nos diz de uma certa sensação de desprazer gerada pelo contato com a Matemática. $\mathrm{Na}$ direção de seu esclarecimento, argumentamos que, com a tecnificação, tudo é consumido

\footnotetext{
${ }^{6}$ Para maiores detalhes veja Vanier (2005).

${ }^{7}$ Em Psicanálise, a pulsão é a energia psíquica que tende a ser investida ou concentrada em um objetivo (uma pessoa, uma coisa, uma causa, o próprio $\mathrm{Eu}$, ...). O termo sexualidade só em sentido estrito refere-se a uma pulsão parcial, relativa aos órgãos sexuais, e o termo Eros e suas variações (erótico, erotização, ...) referem-se a uma pulsão do organismo inteiro, polimorfa.
} 
no ato da ação e as coisas assumem uma forma que restringe a lida com elas à mera manipulação, sem um excedente de liberdade e de tolerância (ADORNO, 2008, p. 36). Ao mesmo tempo, o inconsciente possui uma lógica que não corresponde à lógica clássica própria da formalização e da técnica que produzem estas mesmas coisas.

Sugerimos então a seguinte pergunta: se Lacan define pulsão como uma colagem surrealista $^{8}$, como se dá a manifestação desta pulsão em uma realidade em que não há mais tolerância com o excedente e em que o próprio movimento surrealista representou o avesso de qualquer intencionalidade técnica?

A teoria crítica, antes de dar uma resposta, nos apresenta a dimensão dos fatos. Como a sublimação depende de um alto grau de autonomia, ela é essencialmente mediação: entre o consciente e o inconsciente, entre o intelectual e o pulsional (MARCUSE, 2015, p. 100-101). Porém, há na modernidade o predomínio do estritamente sexual sobre o erótico enquanto inibição das possibilidades sublimativas (MARCUSE, 2015, p. 99). Expressões desta deserotização são a linguagem operacional e a perda da qualidade do trabalho: ambientes radicalmente anti-históricos onde a invocação ritualizada do passado não permite a mediação, isto é, o desenvolvimento do conteúdo recordado (MARCUSE, 2015, p. 118).

A partir disso, ousamos dizer que a imposição de uma realidade deserotizada - e, portanto, sem mediação - pode ser comparada a um sonho incapacitado de se constituir por falta de conteúdo que escape à censura da resistência e, talvez, algo parecido ocorra na incapacitação do pensamento criativo pela inibição do contato com aquelas deformações praticadas na infância com a brincadeira. Certamente ainda não estamos aptos a elucidar tais comparações, mas, independentemente disso, Adorno e Marcuse apontam para as possibilidades de uma intervenção surrealista:

[As pinturas surrealistas] (...) reuniram o que o funcionalismo cobre com tabus porque elas revelam a realidade como reificação e o irracional em sua racionalidade. O surrealismo recupera o que o funcionalismo nega ao homem; as deformações demonstram o que o tabu fez ao objeto de desejo. Assim, o surrealismo resgata o obsoleto - uma coleção de idiossincrasias no qual a exigência de felicidade faz desaparecer aquilo que o mundo tecnificado recusa ao homem (ADORNO apud MARCUSE, 2015, p. 96).

O obsoleto é o único capaz de expressar aquele mundo romântico pré-tecnológico e fornecer conteúdo para a realização de experiência libidinal (MARCUSE, 2015, p. 98). Logo, da mesma forma que o Surrealismo busca dar algum sentido ante ao que se perde na execução

\footnotetext{
${ }^{8}$ A pulsão é uma "colagem surrealista (...) creio que a imagem que nos vem mostraria a marcha de um dínamo acoplado na tomada de gás, de onde sai uma pena de pavão que vem fazer cócegas no ventre de uma bela mulher que lá está incluída para a beleza da coisa” (LACAN, 1964/1985, p. 161).
} 
imediata, as condições para sublimação só parecem possíveis na inclusão de formas outras que não o estritamente lógico e operacional, ou seja, pela inclusão do excedente.

Portanto, a ideia geral, cujas bases iniciais propomos aqui, consiste em denunciar a Matemática moderna em seus aspectos irracionais que culminam na imposição de uma forma de pensamento autoritária, cuja expressão maior está na cisão entre a forma lógica predominante na constituição do pensamento matemático - e a forma estética. Acreditamos que a compreensão de uma forma estética para a Matemática passa a ser fundamental conquanto forneça excedentes para a recuperação da autonomia do pensamento. Autonomia que não está dissociada das possibilidades sublimativas. Freud, por exemplo, ao classificar a perversão em termos de extensões e permanecimentos em metas sexuais intermediárias com relação ao objeto sexual, apresenta o olhar e o tocar como desvios em relação à meta sexual considerada normal, mas dos quais surgem as possibilidades artísticas enquanto sublimação (1905/2017, p. 49-50). Assim sendo, a topologia, pelo menos no que compete às suas origens e motivações iniciais, surge em conexão com a forma surrealista pelas capacidades de colagem, deformação e no apelo a diferentes percepções - o olhar e o tocar, principalmente.

Do exposto, resumimos: (1) a pulsão é uma colagem surrealista (Lacan); (2) na infância, deformações estão relacionadas à brincadeira e, no adulto, à fantasia (Freud); (3) deformação e colagem remetem à constituição da topologia; (4) a geometria e a topologia são negligenciadas nos currículos populares e há um motivo ideológico para isso (Pavanello); (5) há um fechamento social do universo erótico enquanto inibição das capacidades polimórficas das pulsões pela eliminação de todo excedente (Adorno e Marcuse). Conclusão: a geometria e a topologia, em suas capacidades deformativas e perceptivas, possuem uma dimensão mediadora a ser explorada e a recuperação de seus conteúdos pode ser encarada como uma luta política, sendo que o mesmo pode ser estendido a toda Matemática.

\section{As possibilidades das alternativas}

Na modernidade, o estudo científico de um objeto ou fenômeno passa, por meio da observação e experimentação, à criação de modelos pelos quais se determina objetivamente o controle, a reprodução e/ou a generalização desse mesmo objeto ou fenômeno a partir dos resultados obtidos. A descoberta científica, portanto, promove uma certa naturalização através da repetição, de modo que a apreensão automática desses modelos tende a comprometer ou inibir um "segundo olhar" sobre as coisas, numa outra perspectiva ou em um contexto diferente. 
A Matemática, por sua vez, parece reduzida a algoritmos e fórmulas ou, ainda, a ela se atribui um conjunto de saberes específicos (aritmética, álgebra, análise, geometria). Mas qual fundamento pode, por exemplo, aproximar conceitos da álgebra moderna com a construção com régua e compasso da clássica geometria grega? Surpreendente é sabermos que tais relações existem ou podem eventualmente se constituir - nesse caso, o exemplo que nos vem da Teoria de Galois é significativo. Em outras palavras, queremos dizer que, para além de fórmulas ou de um conjunto bem determinado de saberes, uma Matemática séria surge quando podemos negar estas delimitações. Para aquele que a estuda trata-se, portanto, mais de ressignificação do que de (re)produção.

A criança produz ressignificação ao brincar, seu lidar é espontâneo e não está condicionado a exigências. Porém, num mundo em que tudo é consumido no ato da ação, somos desprovidos de material para criação em um duplo sentido: recreação e criatividade. $\mathrm{Na}$ imposição de formas prontas, não há nada a ser deformado e, na totalidade rígida, todo conteúdo é forçado a se encaixar ou perecer: a geometria fixa das coisas nos impõe uma totalidade antitopológica. Mesmo a busca de uma forma estética para a Matemática depende da ampliação do escopo das discussões em Educação Matemática, passando a incluir, por exemplo, a teoria crítica e a psicanálise. Por ora, seguimos Marcuse quanto à compreensão de que uma forma estética é "o resultado da transformação de um dado conteúdo (fato atual ou histórico, pessoal ou social) num todo independente: um poema, peça, romance, etc." (2007, p. 18), tomando a liberdade de incluir neste "etc." uma ideia matemática, ou mesmo um teorema, conquanto que entendamos a Matemática como uma construção social historicamente determinada cujas inspirações só podem surgir a partir de uma subjetividade e autonomia preservadas.

Em tempos de totalidades abusivas e imbecilizantes, as possibilidades podem surgir na crítica à predominância de uma Matemática sem compromisso com o pensamento. Como exemplo, temos a frase maciçamente divulgada: A matemática está em tudo ${ }^{9}$. À luz da Teoria Crítica, somos impelidos a reescrevê-la em uma outra perspectiva, para além da posição condescendente e afirmativa da intenção original. Para tanto, apresentamos o seguinte programa (parcial) para as aulas de Matemática voltadas à formação dos futuros professores de Matemática:

\footnotetext{
${ }^{9}$ A matemática está em tudo foi o tema da Semana Nacional de Ciência e Tecnologia de 2017 e os anos de 2017 e 2018 foram instituídos como o Biênio da Matemática no Brasil.
} 


\section{Programa para uma intervenção surrealista nas aulas de matemática dos futuros}

\section{professores de matemática}

(1) Ler trechos de Pedagogia do Oprimido de Paulo Freire antes de começar a aula.

(2) Exibir o filme Teorema de Pasolini. Outros filmes, como os dos diretores Fellini, Scola, Kubrick, Haneke, Almodóvar, Tarkovski, etc., também são excelentes para apreensão de uma totalidade.

(3) Ler poemas de Manuel de Barros. Ao enfatizarem a singularidade da nossa existência, estes poemas podem sugerir interessantes questões sobre a finalidade da produção científica. (Adendo: do descompasso em relação à pobreza intelectual e material reservada à maioria das pessoas, é provável que a discussão se depare com a ciência burguesa, ficando claro, em particular, que um teorema pode não servir para nada além do tempo despendido da vida para fazê-lo).

(4) No início da disciplina propor aos alunos que escrevam um texto sobre os temas e as perspectivas que ela evoca. Ao final, repita o procedimento e compare com o primeiro texto. (Adendo: talvez pouco ou nada terá mudado e a exceção aí ocorra dos restos proporcionados pelas leituras e filmes).

(5) Sempre falar sobre a história da disciplina ou ramo do conhecimento. Raramente se tem o privilégio de contemplar olhares curiosos como no momento em que se conta uma boa história. Assim, ouvir os alunos e suas histórias deve fazer parte da ementa.

Num primeiro momento, tal abordagem pode gerar uma certa aversão ao leitor e o induzir a uma depreciação da mesma pela acusação de falta de fundamento pedagógico, de ser inapropriada ou mesmo imatura, conduzindo para um abandono/deturpação da Matemática ao invés de um efetivo aprendizado. Entretanto, mais do que ideias que expressam o ridículo em A matemática está em tudo, elas representam exatamente o uso não reificado da afirmação, pois, ao serem logicamente condizentes com o "em tudo" da proposta, surgem as brechas com a qual ganham legitimidade contra qualquer ato que tende, por ímpeto de uma prática educacional "oficinalizada", rejeitá-las. Ao apontar para uma incursão idealista da Matemática em todas as esferas da vivência humana, a própria frase - quando posta à luz pela crítica conduz para aberturas que ela mesma tenta esconder. Em seu discurso reificado impera o comando no embotamento de suas próprias possibilidades:

O que seria diferente é igualado. Esse é o veredicto que estabelece criticamente os limites da experiência possível. O preço que se paga pela identidade de tudo com tudo é o fato de que nada, ao mesmo tempo, pode ser idêntico consigo mesmo. O 
esclarecimento (...) elimina o incomensurável. Não apenas são as qualidades dissolvidas no pensamento, mas os homens são forçados à real conformidade. $\mathrm{O}$ preço dessa vantagem, que é a indiferença do mercado pela origem das pessoas que nele vêm trocar suas mercadorias, é pago por elas mesmas ao deixarem que suas possibilidades inatas sejam modeladas pela produção das mercadorias que se pode comprar no mercado. Os homens receberam o seu eu como algo pertencente a cada um, diferente de todos os outros, para que ele possa com tanto maior segurança se tornar igual. Mas, como isso nunca se realizou inteiramente, o esclarecimento sempre simpatizou, mesmo durante o período do liberalismo, com a coerção social (ADORNO; HORKHEIMER, 2006, p. 23-24).

Na contramão, o Surrealismo surge como recusa e aqui também como um ponto de convergência para um entendimento da Matemática e de sua práxis a partir da Teoria Crítica da sociedade. De fato, a recusa em participar das regras do(s) jogo(s) já constituem uma práxis, mas não podemos nos esquecer, por exemplo, da inspiradora experiência da Universidade Popular Portuguesa e da coleção intitulada Biblioteca Cosmos. Conforme Medeiros e Medeiros, a participação delas na realidade dos operários portugueses exerceu um importante papel na cultura e na resistência antifascista portuguesa até a metade do século XX: "a Universidade Popular era um centro de difusão da cultura, onde ocorriam atividades das mais variadas: concertos, conferências, entrevistas, cursos, peças teatrais e cinema" (2003, p. 263). Brilhantemente organizadas pelo matemático Bento de Jesus Caraça, essas iniciativas sim é que constituem verdadeiras expressões de totalidade ou, melhor, de universalismo, pois no sentido da luta de classes:

Educação é função da luta de classes, mas não apenas isso. Ela coloca, segundo o credo comunista, a avaliação completa do meio social dado a serviço de metas revolucionárias. Mas, como esse meio social não é apenas lutas, mas também trabalho, a educação apresenta-se ao mesmo tempo como educação revolucionária do trabalho. (...) Durante a era Lênin teve lugar na Rússia a significativa discussão a respeito de formação monotécnica ou politécnica. Especialização ou universalismo do trabalho? A resposta do marxismo proclama: universalismo! Apenas enquanto o homem vivencia as mais diferenciadas transformações do meio social, apenas ao mobilizar sempre de novo, em cada novo meio, as suas energias, colocando-as a serviço da classe, apenas assim ele atinge aquela disposição universal para a ação, a qual o programa comunista contrapõe àquilo que Lênin chamou de "o traço mais repugnante da velha sociedade burguesa": a dissociação entre prática e teoria (BENJAMIN, 2014, p.123-124).

Assim como as promessas não cumpridas pela modernidade insistem em reafirmar suas validades, uma aproximação entre Matemática e Surrealismo por meio da crítica a certa concepção absolutista e unidimensional da Matemática não constitui um ato aleatório e despretensioso. De uma forma ou de outra, a construção da crítica é apenas parte da insistência.

\section{Referências}

ADORNO, T. W. Educação após Auschwitz. In: ADORNO, T. W. Educação e Emancipação. São 
Paulo: Paz e Terra, 2012. p. 119-138.

ADORNO, T. W. Introdução à Sociologia da Música. São Paulo: Editora Unesp, 2009.

ADORNO, T. W. Minima Moralia: reflexões a partir da vida lesada. Rio de Janeiro: Azougue, 2008.

ADORNO, T. W.; HORKHEIMER, M. Dialética do Esclarecimento. Rio de Janeiro: Zahar, 2006.

ALEKSANDROV, P. S. Topology. In: ALEKSANDROV, A. D; KOLMOGOROV, A. N.;

LAVRENT'EV, M. A. Mathematics: its contents, methods and meaning. Mineola: Dover, volume 3, 1999. p. 193-225.

BALDINO, R. R.; CABRAL T. C. B. A pulsão em um caso de dificuldade especial em cálculo. Educação e Sociedade, Papirus, v. 49, p. 485-500, 1995.

BALDINO, R. R.; CABRAL T. C. B. Educação matemática conversando com psicanálise. Zetetiké, Campinas, v. 18, Número Temático, p. 621-652, 2010.

BENJAMIN, W. O surrealismo: o último instantâneo da inteligência europeia (1929). In: BENJAMIN, W. Magia e Técnica, Arte e Política: Ensaios sobre literatura e história da cultura. Obras Escolhidas I. São Paulo: Brasiliense, 2012. p. 21-36.

BENJAMIN, W. Uma pedagogia comunista. In: BENJAMIN, W. Reflexões sobre a criança, o brinquedo e a educação. São Paulo: Editora 34, 2014. p. 121-125.

BRETON, A. Manifestos do Surrealismo. São Paulo: Brasiliense, 1985.

COURANT, R.; ROBBINS, H. O que é Matemática: uma abordagem elementar de métodos e conceitos. Rio de Janeiro: Ciência Moderna, 2000.

FRÉCHT, M.; FAN, K. Initiation to Combinatorial Topology. Boston: Prindle, Weber e Schmidt, 1967.

FREUD, S. Além do princípio do prazer (1920). In: FREUD, S. Obras completas, volume 14. São Paulo: Companhia das Letras, 2010. p. 161-239.

FREUD, S. O delírio e os sonhos na Gradiva de W. Jensen (1907). In: FREUD, S. Obras completas. São Paulo: Companhia das Letras, 2016. p. 13-122.

FREUD, S. O escritor e a fantasia (1908). In: FREUD, S. Obras completas. São Paulo: Companhia das Letras, 2016. p. 325-338.

FREUD, S. Três ensaios sobre e teoria da sexualidade (1905). In: FREUD, S. Obras completas. São Paulo: Companhia das Letras, 2017. p. 13-172.

LACAN, J. O seminário, livro 11: os quatro conceitos fundamentais da psicanálise. 2. ed. Rio de Janeiro: Zahar, 1985.

MARCUSE, H. A dimensão estética. Lisboa: Edições 70, 2007.

MARCUSE, H. O Homem unidimensional: estudos da ideologia da sociedade industrial avançada. São Paulo: Edipro, 2015.

MEDEIROS, C. F.; MEDEIROS, A. O pensamento dialético de Bento de Jesus Caraça e sua concepção da educação matemática. Ciência e Educação, Bauru, v. 9, n. 2, p. 261-276, 2003. 
MIGUEL, A. Entre Jogos de Luzes e de Sombras: uma agenda contemporânea para a educação matemática brasileira. Perspectivas da Educação Matemática, Campo Grande, v. 9, n. 20, p. 323$365,2016$.

MUNKRES, J. R. Topology. 2. ed. Prentice Hall: New Jersey, 2000.

PAVANELLO, R. M. O abandono do ensino da geometria: uma visão histórica. 1989. 201 f. Dissertação (Mestrado em Educação) - Universidade Estadual de Campinas, 1989.

PUCCI, B.; ZUIN, A. A. S.; RAMOS-DE-OLIVEIRA, N. (Org.). Ensaios Frankfurtianos. São Paulo: Cortez, 2004.

SKOVSMOSE, O. Educação Matemática Crítica: a questão da democracia. São Paulo: Papirus, 2015.

VANIER, A. Lacan. São Paulo: Estação Liberdade, 2005.

WILLER, C. Prefácio. In: BRETON, A. Manifestos do Surrealismo. São Paulo: Brasiliense, 1985. p. 9-21.

Submetido em 16 de Abril de 2018. Aprovado em 19 de Novembro de 2018. 